\title{
TESTIMONIO SOBRE PABLO DE ROKHA
}

Me corresponde dialogar unos minutos con la figura y la palabra de nuestro padre violento. El mismo que nos vaticinó La república asesinada en 1958 y diez años después cortó su propio oxígeno de un tíro en la boca, el martes 10 de ese otro septiembre, como otra llamarada premonitoria.

En la página 15 de Los gemidos, publicado a los veintiocho años, en 1922, había escrito el autoepitafio:

Aquí yace Juan, el carpintero; vivió setenta y tres años sobre la tierra, pobremente; vio grandes a sus nietos menores, y amó, amó, amó su oficio con la honorabilidad del hombre decente. Odió al capitalista imbécil y al peón canalla, vil o utilitario. Juzgaba a los demás según el espiritu. // Las sencillas gentes honestas del pueblo veíanle al atardecer explicando a sus hijos el valor funeral de las cosas del mundo. Anochecido ya, cantaba ingenuamente junto a la cuna del rorro. Un olor de virutas de álamo o quillay, maqui, litre, boldo y peumos geniales perfumaba el ambiente rústico de la casa. La mujer sonreía. No claudicó jamás, y así fue su existencia. // Así fue su existencia. Ejerció diariamente el grande sacerdocio del trabajo desde el alba, pues quiso ser humilde e infantil, modesto en ambiciones. Los domingos leía a Kant, Cervantes o Job; hablaba poco y prefería las sanas legumbres del campo. Vivió setenta y tres años sobre la tierra; falleció en el patíbulo, POR REVOLUcIONARIO.

De todos los poetas de nuestra promoción, sólo a Nicanor Parra le pareció discutible el gesto senequista, y se atrevió a disparar encima del difunto con la segunda estrofa de su texto Total cero, justo cuando ya el otro no podía, por desgracia, defenderse de haber vivido y muerto como vivió y murió:

Mientras escribo la palabra mientras y los diarios anuncian el suicidio de Pablo de Rokha 


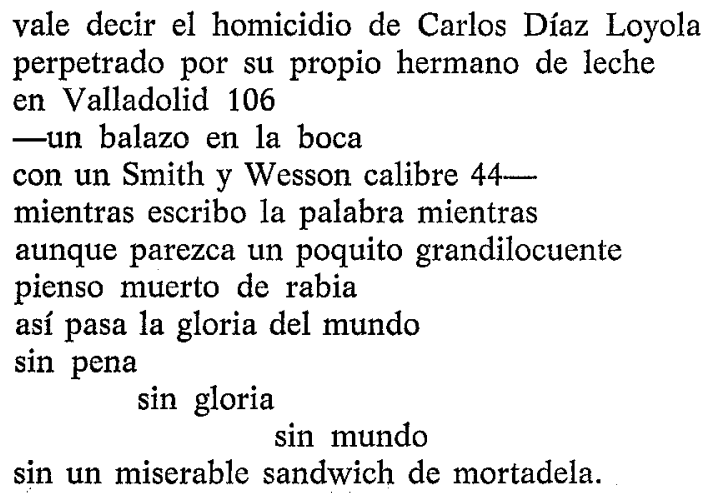

Será cosa de talante, pero discrepo de ese aire irrisorio para hablar de uno de nuestros progenitores. $\mathrm{Y}$ no por adhesión a lo elegíaco: ese hartazgo.

Toda la gracia está en el límite. Así estoy seguro de que el mismo Nicanor, por ejemplo, no ha podido consentir con la última alabanza teológica de Ignacio Valente en El Mercurio del 18 de diciembre pasado, cuando por poner por las nubes esos Sermones y prédicas del Cristo de Elqui lo pone a él en la picota:

«Es éste el único poema mayor que yo conozca escrito integralmente en chileno, no en un simple castellano adobado con pintoresquismos locales. Ni la Mistral, ni Neruda, ni De Rokha, con toda su chilenidad, pudieron ensayar nada semejante. $Y$ como siempre que se da en poesía un lenguaje nuevo, se produce en él una nueva revelación: la de nuestro ser nacional».

Hace unos treinta años, en nuestros diálogos en Los Guindos, el futuro antipoeta y yo nos reíamos de nosotros mismos con la mejor salud del mundo: -Yo soy más sublime que tú. -No, yo soy aquí el único sublime.

Uno piensa en De Rokha o en cada uno de aquellos que sembraron la libertad en nosotros y, por sobre la ventolera de los grupos o más acá, vuelve al frescor de los años de aprendizaje, de los que acaso no debimos haber salido nunca, sin alarde de nada ni mucho menos. $\mathrm{Ni}$ presunción de ser testigo único de aquella promoción poética chilena que contaba veinte años el 38; ese 38 a secas clave de tanto y tanto crecimiento en un Chile rítmico y volcánico a la vez. ¿Qué de extraño entonces que el trato con Altazor y Residencia en la Tierra y esas poéticas de vanguardia tan especialmente francesas nos permitiera oír en el $l i$ - 
berrismo rokhiano un sonido único incorporado con intermitencias a nuestra respiración? Estimable de veras ese término «liberrismo», acuñado para el caso por O. Segura Castro y Julio Molina Núñez en 1917, cuando el poeta cumplía apenas veintiún años, y recogido como propio por Juan de Luigi. Hasta el abuso de regionalismos linguísticos tan en la gracia de su precursor Carlos Pezoa Véliz, su hipertrofia verbal y su «salud de forajido» en el decir nerudiano, lo enorme y lo delicado de su furor poeticus, lo profético, lo bíblico, el fuego negro, nos daban esa fascinación a la que seguramente alude Nietzsche cuando advierte que «a la grandeza va unida la terribilidad, digan lo que digan». Perdón que singularice un matiz, pero reconozco sin reservas que afinidades múltiples me llevaron temprano hacia su órbita por vagamundo y cateador del gran silencio de las cordilleras de Chile desde la mocedad; por, como él, jugarme entero la libertad desde lo hondo del desamparo.

Filiados en un proceso más abierto que el de los adivinos primordiales de nuestro auténtico qué somos («El chileno - escribe Miguel Serrano el 38- mira la cordillera y cree que al otro lado de ella no hay nada»), cada uno de nosotros fue huidobriano y nerudiano simultánea y sucesivamente; fue rokhiano, o aprendiz de brujo más o menos surrealista, u otra cosa. Todo ello en el vaivén de las adhesiones y los rechazos muchas veces gratuito. Lo difícil en ese $38-\mathrm{y}$ no estoy hablando de un año, sino de un ciclo movedizo-, lo casi imposible, era encontrar a un mistraliano en el pajar de tanto hispanizante y afrancesado ciego, por mucho que ese mismo año hubiera aparecido Tala en Buenos Aires con sus materias fundadoras.

Claro que ya la muy conocida Antología de la poesía chilena nueva (Santiago: Zig-Zag, 1935), en la que dentro de los diez únicos de la fama se incluyen los dos antologadores adolescentes, la había excomulgado por ser la suya una poesía «de esencias retardatarias, forjada de supervivencias novecentistas».

Tiempo al tiempo, antólogos presurosos. Pero qué nítido lo que dice allí Volodia Teitelboim con sus escasos diecinueve años: "Por aquel entonces (y ese entonces era el tiempo de las revistas Azul y Musa Joven, 1912-1913), compañero de Vicente Huidobro en sus luchas literarias iniciales, Pablo de Rokha comienza a escribir una poesía sin precedentes en consonancia con una concepción estética palmariamente distinta de la de los demás poetas. Desde Versos de infancia, 1912, hasta Jesucristo, 1922, se afina circulando siempre dentro de la órbita de una personalidad sin confusión posible. Satanás, 1927; Sudamérica, del mismo año, y Escritura de Raimundo Contreras, 1929, son poemas autóctonos (con lo que apuntó a la visión ruralista esencial rokhiana); pero 
pronto su proceso evolutivo deja a la rezaga este estadio vernáculo de su obra... para entrar al compromiso».

He aquí uno de los primeros juicios sin regateos al aporte del autor de Los gemidos, obra que curiosamente coincide con la fecha de la publicación de Trilce y de Desolación. Impresas las cuatrocientas páginas en formato mayor, con la lúgubre carátula de Pedro Celedón por cierta editorial «Cóndor», de la que nunca se supo, dice el poeta que no alcanzó a vender una docena de ejemplares, y la mayor parte de la edición fue adquirida por kilos para los puestos del Matadero. Cosa frecuente oír hablar por ahí de Los gemidos sin más lectura que la de algún texto espigado en esas treinta y cinco piezas en prosa de aspecto informe; prosa de lava líquida, como propuso León Bloy refiriéndose a Los cantos de Maldoror. Y no es que pretendamos establecer parentesco 0 influencia mayor. ¿Conocería De Rokha la traducción de un fragmento de los Cantos, publicado en el número 11 de la revista Vida Nuestra, de Buenos Aires, en mayo de 1919? ¿O sólo vendría a leer la versión de Ramón Gómez de la Serna en 1925? Importante el examen de un estímulo literario como ése, aunque está claro que nuestro autor no leía el francés.

Hay, por cierto, un abolengo profético y apocalíptico común, un desprecio por la medida para llegar siempre más y más lejos, pasado cualquier riesgo del lenguaje, y el humor, ese humor negro, el de las "cabezas de tormenta», como dice Bretón en uno de sus ensayos. Un humor agresivo, destructivo, corrosivo, negativo. Como si el hueco del Dios les exigiera en uno y otro caso la búsqueda sin fin, el proyecto protoplasmático y la apetencia de lo informe, «a la manera de los sentidos desparramados», y el tono moral desde la imprecación y la blasfemia.

Mis pensamientos hacen sonar los siglos contra los siglos; voy caminando, caminando, caminando musicalmente y mis actos son himnos, cánticos naturales, completamente naturales; las campanas del tiempo repican cuando me oyen sentirme; constituyo el principio y la razón primordial de todas las tonadas, el eco de mis trancos restalla en la eternidad, los triángulos paradójicos de mi actitud resumen el gesto de los gestos, el gesto, la figura del superhombre loco que balanceó la cuna macabra del orbe e iba enseñándole a hablar.

Por algo el Neruda juvenil y fraterno de los dieciocho años dice lo que dice al registrar sismográficamente el cataclismo rokhiano como un fenómeno de enriquecimiento elemental desde lo hondo de lo genuino. Oigamos sus palabras en Claridad, órgano oficial de la Federación de 
Estudiantes de Chile, el 16 de diciembre de 1922: «Un impulso hacia la raíz trascendente del hecho, una mirada que escarba y agujerea en el esqueleto de la vida y un lenguaje humano, de hijo de mujer, un lenguaje exacerbado, casi siempre sabio, de hombre que grita, que gime, que aúlla: ésa es la superficie de Los gemidos. Pero libre ya de las palabras, de los alaridos y de las blasfemias, sentimos a un amador de la vida y de las vidas azotado por la furia del tiempo, por los límites de las cosas, corroído hasta la médula por la voluntad de querer y por la horrible tristeza de conocer. ¿Continuador del coro trágico? Tal vez. Lejos de la ataraxia de los socráticos, Pablo de Rokha trasluce su sentido de la vida en una agitación discontinua, que se paraleliza a los cantores de Dionysos. Canta a Prometeo, griego de nacimiento, cuando desata su imprecación al católico Satanás. Y su libro entero es un solo canto, canto de vendaval en marcha que hace caminar con él a las flores, a los excrementos, a la belleza, al tiempo, al dolor, a todas las cosas del mundo, en una desigual caminata hacia un desconocido Nadir».

¿No se ha dicho una y otra vez que los poetas entran con libertad y dominio en la visión de los poetas? Pero De Rokha está esperando todavía la virtud y el rigor de los estudios sistemáticos con las grandes claves iluminadoras. Algo se ha hecho, con Juan de Luigi a la cabeza, su gran amigo, quien muestra los pasos de esta poética desigual sin ahondar suficientemente en ella. Le preocupa, por ejemplo, la herida de esta cosmovisión insistiendo en el demonismo lautreamoniano del poeta de Licantén.

Dice De Rokha en «Demonio a caballo»:

Por entre mundos, entre muertos, entre

edades que desfilan muerte y vientres de siglos, en verde aceite de eternidad, amontonados,

navego, a mil estadios de mí mismo, solo.

No entiendo cómo soy, ni en dónde soy, ni cuándo soy, ni si soy, o yo soy otro, distinto, universal, acumulado, absorto con mis águilas; abajo, un mar vestido de culebra, mordiendo un crucifijo incendiado, un dios de época y piedra,

medio a medio, un tubo de llanto, de luto de atardecer, y, encima, una gran estampa de caballero dellogado...

En un retrato detractor que Alone hace de él en su muy conocida Historia personal de la literatura chilena, cierra con esta frase: «Pero es un hecho que, junto con Huidobro, precedió a Neruda».

Así lo vio la promoción por la que estoy vertiendo este testimonio 
necesariamente parcial. Ahí está, por ejemplo, Teófilo Cid celebrando en él al exponente máximo del amarditamiento como tonalidad afectiva nacional desde un modo de hablar desacralizante, transido siempre por la irreverencia al idioma. "Mardito» o "amarditao» en la jerga de nuestro pueblo es maldito; pero no el maldito verlainiano, sino el endemoniado por el propio alcohol estallante de su laberinto. Ahí está Eduardo Anguita con su tesis del contrapunto del peso y de la gracia, el peso de la noche versus la maravilla, de Neruda y Huidobro, respectivamente, para ceder la síntesis de la vis o de la fuerza (¿no hemos reiterado su genealogía profética?) al maestro De Rokha. Ideas compartidas por Miguel Serrano, Eduardo Molina y otros que hicieron demasiado suyas las Meditaciones sudamericanas, de Hermann Keyserling, en eso de vernos como continente del tercer día de la creación.

Patriarcal como un hidalgo pobre ( Yo me crié comiendo pobreza, pero pobreza acomodada, que es la pobreza más pobreza de todas las pobrezas»), según había escrito el 27 en Heroísmo sin alegría, acogió por igual con su trato viril en sus domicilios ambulante de Avenida Inglaterra o La Cisterna, o de la Reina - donde se mató-, lo mismo a los rokhianos que a los no rokhianos, como era el caso de los surrealistas del Mapocho, que lo encontraban ordinario e ignorante, pero que se tomaban su vino. Todo ello, por supuesto, con el desconsuelo y el fastidio de Carlos, el hijo mayor, un poeta de mi plazo siempre próximo a nuestro grupo que nos fascinaba por su gracia arcangélica. El fue quien desencadenó el suicidio en la familia, inmolado también por la gran búsqueda como alcanzamos a leer en la elegía bellísima de Enrique Lihn.

Días ésos torrenciales y polémicos polarizados en gran medida por nuestros grandes, que veinte años después habríamos de revisar en los encuentros de enero y julio del 58, en Concepción de Chile o en Chillán, para ver cómo nos había ido en la feria, pasado el espejismo de la vanguardia, según dijo Teitelboim desde su experiencia. En su «Resolución de medio siglo», Fernando Alegría planteó otra vez la voluntad de ser nosotros mismos desde el legado de un De Rokha y un Huidobro, de una Mistral, de un Neruda y, por cierto, de otros. Es ése justo el momento en que el viejo Pablo vende por las calles La república asesinada, recién impresa en Idioma del mundo; transportando los volúmenes en carruajes fantasmales arrastrados por algún jamelgo con auriga y todo, como lo ha contado Alfonso Alcalde con maestría.

Canto mi llanto nacional sangrando entre soldados sin pabellón —dicen las últimas líneas de La república asesinada - contra las mé- 
dulas pisoteadas, y comparo el futuro a una máquina de oro en las tinieblas.

Mi nombre es Chile y mi apellido lo infinito.

Solo entre solos, yo vengo saliendo de adentro de la multitud chilena, rememorando la gran hazaña del porvenir.

Sé que hablé demasiado, y aquí vamos cerrando, pero no me aparté del compromiso. Del compromiso del testimonio. Pero no entré en el hondón de su poesía, ni dije nada sobre su sistema imaginario, ni de la paradoja, tan decisiva en su palabra, ni del mecanismo enumerativo y reiterativo, ni de su tránsito por Walt Whitman, ni sobre su proyecto épico pariente o no del muralismo, ni sobre la Epopeya de las comidas y las bebidas de Chile (1950), ni sobre Elegía del macho anciano (1958). $\mathrm{Ni}$ sobre «el loco amor» y su Winett, ni sobre aquella «Carta perdida a Carlos de Rokha» que hay que leer como su escritura toda, con inocencia y rigor, por dispersa que ande en su escándalo paradojo.

Obra la suya destinada al asalto de la posteridad, según el poeta Humberto Díaz-Casanueva, que habrá de ser desenterrada como un palimpsesto.

Errores hasta el hartazgo sin haber aprendido gran cosa de ellos, pero jaguar en el pantano, como dijo Juan de Luigi alguna vez.

De él vinimos por último, de semi-él y de anti-él («naiden rempuje a naiden»), y de otros anti-él. Cantera viva de la que siempre habrá de estar viniendo fresca el agua.

Viéndolo claro en este humo de Chicago, al que cantó a su modo en la página 24 de Los gemidos, corto aquí mi testimonio exiguo con este no. No, él no es un olvidado.

Gonzalo Rojas

Universidad Simón Bolivar,

Caracas (Venezuela). 
